\title{
II. Ueber Asepsis und Antisepsis in der Geburtshülfe.
}

\author{
Von
}

P. Baumm, Breslau.

Die Mortalitätsziffern sind in den Gebärhäusern allgemein und dauernd auf einen Punkt gesunken, mit dem die ärztlichen Leiter beinahe ganz zufrieden sein können. Bezüglich der Morbidität aber bestehen noch grosse Differenzen zwischen den verschiedenen Entbindungshäusern, wenn man unter Morbidität lediglich alle Temperatursteigerungen über $38^{\circ} \mathrm{C}$. ohne Rücksicht auf den weiteren Verlauf versteht. Ob dieser Standpunkt der richtige ist, bleibt eine Frage für sich, auf die ich noch zurückkomme. Genug, man hat sich gewöhnt, alle Wöchnerinnen für krank zu erklären, deren Temperatur auch nur einmal $38^{\circ} \mathrm{C}$. überschreitet. Es ist ferner klar, dass das Fieber der Wöchnerinnen, soweit es von den Geschlechtstheilen ausgeht, ein Wundfieber ist, entstanden durch Infection der dort befindlichen Wunden. Hieraus folgt zweierlei:

1. Wir müssen durch prophylaktische Maassnahmen es dahin $z u$ bringen suchen, dass unsere Wöchnerinnen $38^{\circ} \mathrm{C}$. garnicht oder so selten wie möglich überschreiten. Die Leitung und Methode derjenigen Anstalt ist die beste, die am wenigsten Procent Fiebernde aufzuweisen hat.

2. Fiebert eine Wöchnerin, so muss unsere Therapie dahin zielen, die eingedrungenen Keime unschädlich zu machen. Diejenige Methode ist die beste, die das am schnellsten und ungefährlichsten erreicht.

Ich gehe auf diese Punkte etwas näher ein.

Ich muss gestehen, dass die glänzenden. Statistiken von Mermann, Hofmeier, Leopold, Frommel, Braun, v. Fernwald u. A. lange Zeit meinen Neid erregt haben, denn meine Fieberfrequenz hat sich immer zwischen 20 und 30 pCt. bewegt. Sie 
waren mir gleichzeitig ein quälender Sporn, es den Meistern gleichzuthun. Es ist mir nicht gelungen. Dabei konnte ich mir niemals verhehlen, dass meine Endresultate nicht schlechter waren als anderswo. Meine Wöchnerinnen haben ebenso oft gesund und rechtzeitig die Anstalt verlassen können. Aber ich hatte doch viele Fieberfälle. Das Unerträgliche lag darin, dass ich mir nach der herrschenden Anschauung und den guten Resultaten Anderer sagen musste, hier oder da lässt du es an den nöthigen Cautelen fehlen. Ich habe schärfste Wacht über Erfüllung der Desinfectionsvorschriften und sonstigen hygienischen Anforderungen gehalten, habe verschiedene Desinfectionsmittel, Sublimat, Carbolsäure, Lysol, Creolin versucht, habe präliminare Scheidenspülungen gemacht und wieder fortgelassen - immer dasselbe schlechte Resultat. Allmälig kam die Aera der äusseren Untersuchung bei mir mehr und mehr in Aufschwung. Wir lernten die Entbehrlichkeit der inneren Untersuchung für die meisten Geburtsfälle kennen. Seit einigen Jahren habe ich zu Zeiten, wo das Anstaltsmaterial nicht zu Lehrzwecken gebraucht wird, die innere Untersuchung nur bei strenger Indication vornehmen lassen (cf. hierüber Deutsche med. Wochenschr. 1895. No. 30). Auf diese Weise habe ich eine ziemlich grosse Reihe Curven von Wöchnerinnen gesammelt, die niemals innerlich berührt worden sind.

Man hat den Anstalten mit hoher Morbidität den Vorwurf gemacht, dass von ihnen die Desinfection nicht streng genug gehandhabt werde. Die Ahlfeld'sche Selbstinfectionslehre galt ja nichts. Die fiebererregenden Keime sollten während der Geburt, bezüglich kurz vor- oder nachher zumeist durch unsere Hände eingeschleppt sein. Ist das richtig, dann mussten die innerlich nicht berührten Wöchnerinnen dies in ihren Curven zum Ausdruck bringen. Um dies an der Hand eines grösseren klinischen Materials klarzustellen, hat sich mein Assistent, Dr. Saft, der Mühe unterzogen, die hierzu nöthige Sichtung unseres Materials vorzunehmen und in dem vorstehenden Aufsatz zu veröffentlichen.

Will man innerlich Untersuchte und Nichtuntersuchte mit einander vergleichen, so müssen in beiden Reihen die Geburten im Uebrigen unter denselben Cautelen geleitet sein. Meine jetzige Methode hat, wie erwähnt, ein längeres Entwicklungsstadium durchgemacht, und ist erst seit meiner Uebernahme der Breslauer Hebammen-Tuehranstalt stabil geworden. Deswegen sind meine früheren Beobachtungen in der vorstehenden Arbeit des Dr. Saft, auf die 
ich mich des Weiteren stützen werde, unberücksichtigt geblieben. Was dadurch an Zahl verloren geht, wird reichlich durch Genauigkeit der Beobachtungen aufgewogen.

Wir sehen nun, dass auch unsere innerlich nicht berührten Wöchnerinnen eine hohe Morbiditätsziffer aufweisen (21,4 pCt). Mir kommt das nicht äberraschend. Auf Grund meiner täglichen Beobachtungen hatte ich immer den Eindruck, dass zwischen Untersuchten und Nichtuntersuchten kein wesentlicher Unterschied bezüglich der Fieberfrequenz besteht. Teh habe dieser Ansicht früher bereits (Deutsche med. Woehensehr. 1895. No. 30) Ausdruck gegeben. Zudem hat $v$. Winckel schon lange auf die hohe Fieberfrequenz nach Sturzgeburten, also ebenfalls bei Ausschluss der inneren Untersuchung, hingewiesen; v. Szabo (Areh. f. Gyn. Bd 36), Fuld (v. Winckel, Die Königl. Universitätsfranenklinik in München), Koch (Arch. f. Gyn. Bd. 29) haben seine Befunde bestätigen können.

Wenn ich die inneren Geschlechtstheile garnicht berühre, so ist das mindestens nicht schädlicher, als wenn ich mit selbst tadellos desinficirten Fingern innerlich untersuche. Wenn ich demnach bei innerlich nicht Untersuchten 21,4 pCt. Morbidität habe und Andere trotz innerlicher Untersuchung nur 6 pCt. oder noch weniger, so ist dies ein Widerspruch, der unwiderstehlich zur Kritik herausfordert. Er muss um so crasser erscheinen, als es uns heut nicht mehr zweifelhaft sein kann, dass unsere bisherigen Desinfectionsmethoden ungenügend sind. Diejenigen, welche die schlechten Statistiken haben, werden natürlich ein besonderes Interesse an der Aufklärung dieses Widerspruches haben. Kö:nen sie doch hoffen, dass damit der ihnen gemachte Vorwurf, mangelhaft sich desinficirt zu haben, schwindet. Bis jetzt war im Wesentlichen nur Ahlfeld der unermüdliche Streiter im Kampf zur Vertheidigung und Rechtfertigung hoher Morbiditätsziffern im Wochenbett. Nachdem ich sieben Jahre lang mich gemüht, mannigfach geärgert und immer wieder fleissig beobachtet habe, sind meine Anschauungen über den in Rede stehenden Gegenstand zu gewissem Abschluss gekommen. Ich will sie in Nachstehendem entwickeln.

Machen wir uns zunächst klar, welche Gegenstände überhaupt in der Geburtshülfe als Infectionsträger in Betracht kommen. Es sind im Wesentlichen unsere Hände, Geräthschaften, Wasser, Wäschestücke, Luft, das Secret der Genitalien und schliesslich die Bedeckung der äusseren Geschlechtstheile und deren Umgebung. 
Andere Dinge (der begattende Penis, unberufene Hände etc.) kommen nur ganz ausnahmsweise in Betracht und können die Statistik kaum beeinflussen. Unsere Hände und Instrumente fallen bei innerlich nicht Berührten weg. Das Secret der Genitalien bleibt dasselbe, ob ich innerlich untersuche oder nicht, vorausgesetzt, dass ich im Uebrigen Geburt und Wochenbett gleichmässig: leite. Wasser, Wäsche und Luft bedrohen erfahrungsmässig in reinem, frischem Zustande nicht die Gesundheit. Wir können also auch über diese Dinge hinweggehen. Ich setze als selbstverständlich voraus, dass jeder Anstaltsleiter für tadellose Beschaffenheit dieser drei Factoren zu sorgen versteht. Es bleiben also bei innerlich nicht Untersuchten lediglich die äusseren Geschlechtstheile übrig, von deren Beschaffenheit unsere schlechte Statistik abgeleitet werden könnte. Aber das geht auch nicht an, denn wir baden jede Kreissende und desinficiren zum Ueberfluss die äusseren Geschlechtstheile und deren Umgebung, nachdem vorher unsere Hände mit Sublimat oder 3 proc. Carbollösung desinficirt worden sind. Ich sage zum Ueberfluss. Nach meiner Ueberzengung würden wir auch ohne Desinfection der änsseren Geschlechtstheile kein schlechteres Resultat erzielen. Es ist ganz genügend, dass den Hebammen in Preussen nur Seifenwaschung, nicht Desinfection, der Geschlechtstheile, zur Pflicht gemacht ist. Ich desinficire mehr zu dem Zweck, mein Personal in der Finübung peinlichster Sauberkeit zu erhalten. Beilüufig möchte ich noch weiter gehen und behaupten, dass der Schmutz der äusseren Genitalien überhaupt meist unsehuldiger Natur ist. Er gehört zu dem alltäglichen Hausschmutz. Dass der nicht viel Unheil anzurichten im Stande ist, lehrt die tägliche Erfahrung bei Geburten in unsauberen Haushaltungen. Selbst die Gefahr des Bacterium coli schätze ich nicht so hoch, als vielfach geschieht. Sicherlich wird es häufig beim Dammschutz, bei Wendungen, Ausziehungen etc. vom Damm aus in den Genitalschlauch gebracht, ohne dass schwere Infection folgt. Es wäre auch eine unverständliche Grausamkeit der überall zweckmässig waltenden Natur, den lauernden Feind so vor's offene Thor zu postiren. Inter urinam et faeces nascimur und zwar in der Regel obne Gefahr für die Yutter, wenn, wie wir noch zeigen werden, unsere Polypragmasie den natürlichen Vorgang nicht stört.

Soviel steht also für mich jetzt fest, dass die glänzenden Resultate mancher Anstalten nicht das Resultat ihrer überlegenen 
Handhabung der Desinfection sind. Woher aber die grossen Unterschiede?

Des Räthsels Lösung vermuthet Ahlfeld ganz richtig in falscher Temperaturmessung Seitens jener scheinbar glücklicheren Anstalten. Den Beweis dafür erblicke ich in dem Resultat unserer innerlich nicht berührten Wöchnerinnen. Unter günstigeren Bedingungen kann sich keine Wöchnerin befinden - und doch 21,4 pCt. Morbidität!

Es kommt eben darauf an, wie gemessen wird. Alles, was Ahlfeld darüber sagt, trifft durchaus zu; ich will es nicht wiederholen. Es muss peinlich genau gemessen werden. Die Messung in der Achselhöhle ist zu wissenschaftlichen Untersuchungen wenig zu gebrauchen. Die nöthige Exactheit ist dabei garnicht oder nur sehr schwer zu erzielen, vom Wartepersonal überhaupt nicht. Man muss im Mastdarm messen, wie wir dies von jeher thun. Die Fehlerzahl sinkt hierbei auf ein Minimum herab. Ich bin sicher, dass, wenn diese Art Messung auch von denjenigen Collegen eingeführt wird, denen eine Morbidität über 20 pCt. etwas Unerbörtes ist, dann auch sie dieselben Resultate werden verzeichnen müssen, wie wir, v. Winckel, Ahlfeld u. A. Es ist hohe Zeit, dass endlich einmal über eine so gewöhnliche Frage, wie die der Temperaturverhältnisse bei Wöchnerinnen, Klarheit geschaffen wird. Dazu gehört einheitliche Art der Temperaturmessung. Man wähle die Mastdarmmessung als die zuverlässigste. Sie ist sicher einfacher als die von Ahlfeld empfohlene Achselhöhlenmessung unter steter Controle durch einen Arzt. Die Mastdarmmessung sollte wenigstens eine Zeit lang allgemein durchgeführt werden, bis das nöthige wissenschaftliche Material beisammen ist. Dann mag man zu der decenteren Messung in der Achselhöhle zurückkehren. Für die Praxis genügt auch diese vollständig. Die Mastdarmmessung ergiebt auch, von zuverlässigem Wartepersonal ausgeführt, die wünschenswerthe Genauigkeit. Dazu gehört aber noch Eins. Es darf nicht jede Temperaturerhöhung mit einer Nachlässigkeit der Pflegerin identificirt werden. Man gebe nie die Parole aus: Wehe, wenn die Temperatur über $38^{\circ} \mathrm{C}$. steigt! Dann wird man sicher betrogen, oder man muss selbst messen. Seitdem ich gesehen habe, dass auch bei unberührten Wöchnerinnen bei zuverlässiger Wartung Temperaturen ïber $38^{\circ} \mathrm{C}$. nichts Ungewöhnliches sind, hüte ich mich, letzteres der Hebamme oder Wärterin in die Schuhe 
zu sehieben, so lange ich -- bei solbstverständlich schärfster Controle - kcinen Beweis dafür habe.

Es gährt übrigens unter den scheinbar abgeklärten Inschauungen der Geburtshelfer. Die Erkenntniss, dass genaueres Messen höhere Morbidität erzielt, dass also Ahlfeld schliesslich doch Recht behält, bricht sich mehr und mehr Bahn und wird zweifellos in nicht ferner Zeit allgemein sein.

Es fragt sich nun, wie kommt cs, dass von den innerlich nicht berührten Wöchnerinnen mehr als jede fünfte $38^{\circ} \mathrm{C}$. überschreitet? Einsehleppung giftiger Keime durch Hände und Instrımente etc. ist ausgeschlossen. Und doch handelt es sich gewiss auch hier um eine Infection, oder ich will genauer sagen - demn der Begriff Infection wird noch nicht einheitlich definirt - um den Uebergang eines Giftes in das Blut. Welcher Art dieses Gift ist, will ich unentschieden lassen; jedenfalls aber stammt es aus den mit Mikroorganismen verunreinigten Wunden der Geschlechtstheile. Ich glaube nicht, dass eine andere Erklärung herangozogen werden muss. Speciell möchte ich hier von dem sogenannten aseptischen Resorptionsfieber absehen. Wir können auch ohne die etwas gezwungene Annahme eines solchen uns alle Vorgänge erklären. - Woher kommen nun diese schädlichen Microorganismen? Da wir sie nicht eingeschleppt haben, können es nur die Keime sein, die sich von Natur aus in der Scheide befinden. Das muss ich auf Grund unserer klinischen Beobachtungen annehmen, so lange es keine bessere Erklärung giebt. Natürlich sind diese Keime nicht durch Autogenesis in der Scheide entstanden, sie sind gelegentlich durch Aussencontact hineingerathen. Das lässt sich nicht rermeiden. Ich nehme also auch eine Selbstinfection an und spreche da von einer solchen, wo keine fremden Gegenstände kurz vor oder während der Geburt und im Wochenbett die schädlichen Keime eingeschleppt haben können.

Warum fiebern nun nicht alle Wöchnerinnen? bei allen giebt es doch Wunden und Mikroorganismen in der Scheide. Einfach deswegen, weil nicht alle diese Keime giftig sind. Das hat auch das Studium der Scheidenflora ergeben. Man hat neben unschuldigen Pilzen auch virulente, namentlich in kranken Scheiden, gefunden. Aus der verschiedenen Intensität der Erkrankungen müssen wir ferner schliessen, dass auch die virulenten Keime sehr verschiedene Giftigkeit entfalten. Ich komme auf die Ursachen daron noch zurück. Genug, unsere Beobachtungen an nicht berührten 
Wöchnerinnen lehren, dass es in der Scheide ungiftige und mehr oder weniger giftige Keime giebt.

Wenn wir den Einfluss der letzteren auf den Wochenbettsverlauf studiren wollen, so brauchen wir nur das reine Beobachtungsmaterial unserer innerlich nicht berührten, fiebernden Wöchnerinnen ansehen. Sie sind auch in der Folge völlig unberührt geblieben. Die Behandlung war rein symptomatisch, nie local. Da haben wir eine weitere, sehr wichtige Wahrnehmung gemacht: Keine einzige dieser Wöchnerinnen - bisher über $500^{1}$ ) an Zahl ist schwer erkrankt. Immer war der Krankheitsverlauf mild, und in kürzester Zeit sank die Temperatur zur Norm herab. Nachkrankheiten, speciell Exsudate, sind nie vorgekommen. Ich habe mich daher gewöhnt, bei allen innerlich unberührten Wöchnerinnen stets eine günstige Prognose zu stellen. Selbst hoch einsetzendes Fieber macht mich nicht irre. Ich weiss, die Frau wird bald gesund, wenn ich ihre Genitalien weiter in Ruhe lasse und auf diese Weise die natürlichen Heilfactoren zur vollen Wirkung kommen lasse. Vorläufig bringen mich auch Leopold's nicht untersuchte Fälle mit tödtlichem Ausgang nicht von dieser Ansicht ab. Sie sind mit Uterusspülungen behandelt worden, daher kein reines Beobachtungsmaterial. Indessen wird wohl auch hier, wie überall, keine Regel ohne Ausnahme sein. Ich warte schon lange auf einen Fall, der meine obige Ansicht widerlegt. Neulich glaubte ich schon einen solchen vor mir zu haben. Eine innerlich nicht untersuchte Wöchnerin begann zu fiebern, während sich eine Thrombophlebitis am Bein entwickelte. Aber die Erkrankung betraf nur die oberflächlichen Venen derart, wie man es auch bei Schwangeren findet. Die Krankheit blieb im ganzen Verlauf mild. Freilich wurde die Wöchnerin lange im Bett gehalten aus Furcht vor Embolien. - Sollte mir wirklich einmal ein Todesfall oder ein schwerer Erkrankungsfall bei einer innerlich unberührt gebliebenen Wöchnerin begegnen, dann bleibt es nur ein seltener Ausnahmefall von der Regel. Ich kann, glaube ich, schon nach den bisherigen Beobachtungen den Grundsatz aufstellen: Innerlich nicht berührte Wöehnerinnen bekommen wohl Fieber, aber niemals ein gefährliches.

1) Anmerk. Die neu hinzugekommenen ca. 200 hat Saft nicht mehr berücksichtigen können. 
Das festzustellen scheint mir hervorragend wichtig. Es ergiebt sich daraus, dass die Scheidenkeime von vornherein $z$ war nicht unschädlich, aber ungefährlich sind. Mag man auch Staphylokokken und Streptokokken in der Scheide gefunden haben und seine theoretischen Schlussfolgerungen daran geknüpft haben, - die klinische Erfahrung steht höher. Sie lehrt, dass dieser Sorte von pathogenen Keimen nicht die gewöhnliche Virulenz innewohnen kann. Bokelmann's Ausspruch von der Asepsis gesunder Frauen bleibt mit einiger Modification zu Recht bestehen. Practisch bleibt es gleich, ob die Kreissende ungiftige Keime in sich birgt oder nur so wenig gittige, dass sie Gesundheit und Leben nicht gefährden.

Dass die Scheidenkeime unter besonderen Bedingungen eine höhere Virulenz erreichen können, ist nicht zu bezweifeln. Man weiss längst, dass die Virulenz der Mikroorganismen sich mit dem Nährboden ändert. Eine klinisehe Illustration dazu giebt auch unser Material:

Wir sehen nämlich, dass Zahl und besonders die Sehwere der Fieberfälle mit den Manipulationen an den inneren Geschlechtstheilen wächst. Innerlich nicht Berührte ergeben 21,4 pCt. Morbidität, die nur Touchirten 25,26 pCt. und die Operirten $39,85 \mathrm{pCt}$. Bei der ersten Gruppe finden sich 3 pCt. mit höherem Fieber, bei der zweiten 9 pCt. und bei der dritten 16 pCt. Woher kommt das?

Am näehsten und daher am verbreitetsten ist die Annahme, dass mit Fingern und Instrumenten pathogene Keime eingeschleppt werden. Das kann aber bei unserem Material nicht die alleinige Ursache sein. Die Instrumente kann man durch Auskochen zuverlässig sterilisiren. Wir haben das vor jeder Operation gemacht. Die Infection durch Instrumente ist demnach auszuschliessen, und es bleibt nur die Vebertragung pathogener Keime durch die Hände übrig. Wie erklärt sich damn aber die bedeutende Zunahme der schweren Fieberfälle bei operirten Frauen im Vergleich zu den nur Touchirten? Unsere Hände sind doch immer gleichmässig desinficirt worden, vor Operationen eher mit vermehrter Sorgfalt, wenn dies überhaupt noch möglich war. Es giebt nur eine Erklärung: Nach Operationen finden eine Menge bedingt giftiger Keime in dem gequetschten, absterbenden Gewebe, in dem Wundsecret, das in den gerissenen Buchten und Löchern stagnirt, einen Nährboden, der ihre Virulenz zur Entfaltung kommen lässt. Nach 
glattem Geburtsverlauf fehlen diese günstigen Bedingungen. Die bedingt giftigen Keime schlummern weiter oder kommen nur zu schwacher Entwickelung. Wahrscheinlich unterliegen sogar manche ausgesprochen giftige Keime der bactericiden Kraft der Scheide, wenn sie nicht in zu grosser Menge eingeführt werden.

Auch pathologische Veränderungen der Scheide geben wahrscheinlich sehr häufig günstige Wachstbumsbedingungen für giftige Keime. Dass Wöchnerinnen mit eitrigem Ausfluss häufiger und schwerer erkranken als in dieser Beziehung gesunde Frauen, dürte kaum zweifelhaft sein. Auf dieselbe Weise sind die unzweifelhaft häufigeren und schwereren Fieberfälle bei zurückgebliebenen Eitheilen ${ }^{1}$ ) oder die Fieberfälle bei todtfaulen Früchten nach vorzeitigem Wasserabfluss zu erklären. Bleibt eine Frau unter diesen Umständen fieberfrei, was nicht selten vorkommt, so beweist das nur, dass hier zufälliger Weise keine virulenten Keime im Genitaltractus vorhanden waren.

So erkläre ich mir auch viele Fieberfälle nach innerlicher Untersuchung. Ungeschicktes Untersuchen muss ähnlich wirken, wie eine Operation. Durch das unmässige Herumbohren und Drücken werden nicht nur Verletzungen - ein günstiger Nährboden - gesetzt, sondern Keime, die vielleicht sonst unschädlich geblieben wären, werden direkt eingeimpft. Ich glaube dies beobachtet zu haben: Es häuften sich beim Antritt eines neuen Assistenten auf dem Gebärsaal auffallend die Fieberfälle, obwohl dieser Assistent sich vorzüglich desinficirte und strenge Controle auf seiner Station übte. Es fiel mir aber auf, das bei der Gründlichkeit des gesammten Verfahrens dieses Herrn auch die innere Untersuchung gar zu energisch von Assistent und Schülerinnen vorgenommen wurde. Diesem Uebereifer wurde abgeholfen und die Fieberfrequenz sank wieder.

Von den Scheidenkeimen haben wir also nur dann etwas zu befürchten, wenn ein besonders günstiger Nährboden für sie vorhanden ist. Dieser Nährboden wird meist künstlich durch Verletzungen der gesunden Genitalschleimhaut geschaffen. Das müssen wir demnach vermeiden. Es geschieht am sichersten durch Unterlassung aller inneren Eingriffe, also auch der inneren Untersuchung, soweit sie nicht ganz schonend

1) Anmerk. Zurückgebliebene Eihautfetzen entferne ich nur, wenn mehr als die Hälfte zurückbleibt. 
ausgeführt werden kann. Immer aber können wir diese Abstinenz nicht durchführen. Es fragt sich dann, ob es nicht möglich ist, die Scheidenkeime unschädlich zu machen.

Es liegt nahe, die von den Scheidenkeimen drohende Gefahr dadurch zu beseitigen, dass man die inneren Geschlechtstheile desinficirt. Man hat sich auch wirklich bemüht - und thut es noch durch Spülungen und Wasehungen die Scheide Kreissender keimfrei zu machen. Ich halte davon Nichts. A priori schon wiederstrebt mir die Annahme, dass bei einem physiologischen Vorgange es nöthig wäre, mit unserer Weisheit dazwischen zu kommen. Die Scheidenspïlungen leisten überhaupt wenig. Muss einen schon die theoretische Erwägung von der Fruchtlosigkeit derselben überzeugen, so hat Steffek direkt nachgewiesen, dass nach blossen. Spülungen das Scheidensecret eine Menge Culturen aufgehen lässt. Dementsprechend hat auch die klinische Erfahrung gelehrt, dass präliminare Scheidenspülungen zum mindesten überflüssig sind. Auch ich habe eine lange Aera der prophylaktischen Scheidenspülungen durchgemacht. Allerdings waren dies alles Fälle, bei denen innerlich untersucht oder operirt wurde. Die Fieberfrequenz der Jahresberichte zeigte die gewöhnlichen (zufälligen) Schwankungen von einigen $20 \mathrm{pCt}$., sank aber nicht dauernd unter die bei NichtAusgespülten gefundene Zahl. Daher habe ich seit Jahren keine Ausspülungen mehr vor der inneren Untersuchung gemacht. In neuerer Zeit haben Leopold und Krönig grössere Reihen Gespülter und Nicht-Ausgespülter zusammengestellt. Das Resultat fiel zu Gunsten der Letzteren aus. Die Einwände, die man Ahlfeld, dem eifrigsten Verfechter der präliminaren Scheidenspülungen, entgegen halten kann, hat Saft bereits erwähnt.

Ich bin noch weiter gegangen und spüle auch vor geburtshülflichen Operationen seit einiger Zeit nicht mehr aus. Ich sage mir: durch Ausspülung allein kann ich keine Scheide keimfrei machen. Ich muss sie desinficiren wie vor einer gynäkologischen Operation. Das zu thun hat aber nur einen Zweck, so lange das Innere der Gebärmutter für keimfrei gelten kann. Diese Voraussetzung besteht selten, nämlich solange der Muttermund noch eng ist, z. B. bei Einleitung der künstlichen Frühgeburt; da desinficire ich die Scheide nach allen Regeln der Kunst. - Ich will nun nicht sagen, dass diese meine Ansicht erwiesen richtig ist; aber die theoretische Erwägung spricht dafür. Den Beweis muss der praktische Erfolg bringen. Soweit bin ich noch nicht, um mit 
Zahlen aufwarten zu können. Wenn ich eine grössere Reihe Operationen ohne Spülung beisammen habe, dann will ich eine Serie nach denselben Principien geleiteter operativer Fälle vorher ausspülen. Es kommt mir vorläufig darauf an, reines Beobachtungsmaterial zu sammeln. Soviel kann ich aber schon heute sagen, dass seit Fortlassen der Spülungen bezüglich Auswaschungen vor Operationen die Resultate nicht schlechter zu sein scheinen.

Auch nach der Entbindung werden keine Spülungen gemacht, aus derselben Erwägung heraus, wozu noch die Befürchtung kommt, man könnte durch die Spülung die giftigen Stoffe weiter hinauf und in's Gewebe hineintreiben. Nur wo es sich um stinkenden Inhalt der Gebärmutter unter der Geburt handelt, mache ich noch. hinterher eine Gebärmutterausspülung; vielleicht auch ohne Zweck und nicht ganz entsprechend unserer sonstigen Anschauung. Aber ich habe in einem Falle von Tympania uteri, bei dem die nachfolgende Uterusspülung fortblieb, den Tod folgen sehen. Vielleicht wäre der mütterliche Körper im Kampfe mit den Mikroben Sieger geblieben, wenn man letzteren den günstigen Nährboden, die noch in grösserer Menge zurückgebliebene Jauche, der Hauptmasse nach durch Wegspülen entzogen hätte.

Man ist weiter gegangen und hat gemeint, durch gründliche Auswaschung des Genitalcanals Keimfreiheit zu erzielen. Es ist bekannt, dass Steffek empfohlen hat, erst die Scheide und womöglich den zugänglichen Cervixabschnitt gründlich mit 2 Fingern und 3 procent. Carbollösung auszuwaschen und - weil sich bald wieder Keime vorfinden -- alle 2 Stunden eine Scheidenspülung mit demselben Desinficiens folgen zu lassen. Dadurch will er immer Keimfreiheit und vorzügliche Wochenbetten erzielt haben. Zunächst zweifle ich noch an der Richtigkeit oder besser an der richtigen Deutung seiner Befunde. Es fehlt noch die Bestätigung durch Nachprüfung von anderer Seite. Ich will diese Nachprüfung nicht vornehmen, aus folgendem Grunde: Eine Scheide kann ich nur dann mit meinen Fingern keimfrei waschen, wenn diese selbst keimfrei sind. Wir wissen aber jetzt, worauf ich noch zurückkomme, dass dies mit unseren bisherigen Desinfectionsmethoden nur zu oft nicht erreicht wird. Wie kann dann also die Scheide nach Auswaschung mit solchen Fingern immer keimfrei sein?! und wie soll man es wagen, mit nicht sicher keimfreien Fingern die Seheidenschleimhaut so grob zu insultiren? Ferner finden sich. 
nach seinen eigenen Angaben auch nach gründlichster Waschung schon 1 Stunde später wieder Keime in der Scheide. Ich kann nicht verstehen, warum jetzt eine Scheidenspülung genügen soll, die Keime wegzubringen, während es sonst nicht möglich ist. Und gesetzt auch, seine Untersuchungsbefunde wären unanfechtbar, so sind doch seine darauf basirenden Vorschläge für die allgemeine Praxis, speciell die der Hebammen, unbrauchbar. Abgesehen von der ungeheuren Belästigung der Kreissenden wäre es geradezu ein Unheil, wenn den Hebammen bei ihrer vielfachen Unzuverlässigkeit in puncto Desinfection nicht nur erlaubt, sondern sogar geboten wäre, alleweil in den Geschlechtstheilen herumzubohren. Ich stehe wohl nicht allein mit dieser Ansicht, denn ich habe nicht gehört, dass Steffek mit seinen Vorschlägen Anklang gefunden hätte.

Wir können demnach nicht den Methoden das Wort sprechen, welche darauf abzielen, den Genitalschlauch während der Geburt keimfrei zu machen. Wir unterlassen daher auch die prophylaktischen Scheidenspülungen und Auswaschungen. Wir vertrauen vielmehr den natürlichen Schutzvorrichtungen und stören diese sowenig wie möglich.

Eine andere Gefahr und, wie allgemein angenommen wird, die Hauptgefahr droht den Wöchnerinnen durch die mit fremden Gegenständen, besonders mit den Fingern, eingeschleppten pathogenen Keime. In wie weit sind diese zur Erklärung der Fieberfälle heranzuziehen und wie machen wir sie am besten unschädlich?

Da haben wir eine sehr wichtige Beobachtung gemacht: Auf Ahlfeld's Anregung habe ich den Erfolg unserer Desinfection in einer Reihe von Fällen geprüft. Es wurden von der desinficirten Hand Hautschuppen mit einem sterilen Hölzchen abgekratzt und in Bouillonröhrchen geworfen. Ich fand nach Lysoldesinfection (2 pCt.) in 16 Fällen nur 2 mal, nach Carboldesinfection ( 3 pCt.) in 21 Fällen $10 \mathrm{mal}$ und nach Sublimatdesinfection (2 pM.) in 40 Fällen $23 \mathrm{mal}$ sterile Hände. Da wir in der Regel nur Sublimat oder Carbolsäure angewandt haben, muss ich annehmen, dass fast in der Hälfte aller Fälle unsere Hände ungenügend desinficirt waren. Und doch haben wir bei den innerlich Untersuchten (nicht Operirten) nur knapp 4 pCt. mehr Fieberfälle aufzuweisen als bei den innerlich nicht Untersuchten. Wie erklärt sich das?

Man könnte sagen, dass 1. die an den Fingern sitzen gebliebenen Keime meist nicht pathogener Natur gewesen seien. Das 
mag zum Theil zutreffen, kann aber nicht allein der Grund sein. Denn thatsächlich sind sehr oft pathogene Keime im Spiel gewesen. Das Jehren die operativen Fälle, bei denen micht anders desinficirt wurde. Man kann wohl kaum annehmen, dass hier nur Scheidenkeime ihr Spiel trieben. Es bleiben noch zwei weitere Erklärungen übrig: 2. Entweder waren die eingeführten Keime nur bedingt pathogen und fanden in Folge der meist schonend ausgeführten inneren Untersuchung nicht den nöthigen Nährboden, um Fieber zu bedingen, oder 3. die an den Fingern haftenden Keime sind gar nicht oder nur in minimaler Menge in der Scheide abgelagert worden. Das erseheint plausibel. Was Bürste und Seife nicht wegbringen, wird schwer dureh den blossen Contact mit der Schleimhaut der Scheide dort in nennenswerther Menge zurückgehalten werden. Dass es aber auch auf die Menge ankommt, ist wohl sicher. Die Frage steht noch offen, wieviel z. B. Streptokokken dazu gehören, um Fieber zu bewirken. Einer thut es gewiss nicht. - Alle drei Momente wird man heranziehen müssen, um zu verstehen, warum trotz unserer höchst ungenügenden Desinfection nicht öfter Fieber bei den innerlich nicht Untersuchten aufgetreten ist.

Immerhin ist das Resultat bei innerlich Untersuchten schlechter, namentlich bezüglich der Schwere der Erkrankung, als bei den unberührt Gebliebenen. Was bei dem Plus jedesmal Schuld war, ist ausserordentlich schwer zu entscheiden. Waren es die eingeschleppten Keime an sich, oder war es erst der durch die innere Manipulation veränderte Nährboden, der die eingeschleppten oder in der Scheide ruhenden Keime zum Aufleben gebracht hat? Wenv. ich aber die Thatsachen zusammenhalte: 1. Unberührte Wöchnerinnen fiebern häufig; aber leicht; 2. innerlich Untersuchte fiebern nur wenig öfter, aber häufiger schwer; 3 . Operirte fiebern viel öfter und schwerer, als die zwei vorigen Gruppen, und 4. unsere prophylaktischen Maassregeln sind immer dieselben und gleichmässig sorgfältig bezüglich mangelhaft gewesen - so bin ich geneigt, anzunehmen, dass der durch innere Eingriffe veränderte Nährboden den Löwenantheil der Schuld trägt, mehr als unsere unvollkommene Desinfection.

Nichtsdestoweniger wird man darnach streben müssen, die subjective Asepsis mehr und mehr zu vervollkommnen, um von dieser Seite nach Möglichkeit jede Infection auszuschliessen. So lange wir aber keine zuverlässige Desinfectionsmethode besitzen, 
werden wir am besten jeden inneren Eingriff vermeiden. Wir behalten dann wenigstens ein reines Gewissen, wenn ein Unglücksfall geschehen sollte.

Sollte es uns jedoch gelingen, unsere Finger sicher zu desinficiren, so ist allerdings nicht einzusehen, was eine ganz schonende innere Untersuchung schaden sollte. Wir würden. ferner bei Ausschluss jeder Infection durch Aussencontact neues, werthvolles Material gewinnen, das mit unserem heutigen verglichen, Klarheit über die Bedeutung der Scheidenkeime für den Wochenbettsverlauf bringen müsste. Damit komme ich auf die Frage nach der besten Desinfectionsmethode.

Die Frage ist in jüngster Zeit brennend geworden. Bisher galt das Sublimat als unübertroffen. Dem Sublimat wohnt eine so hohe bactericide Kraft inne, dass man sich vollkommen sicher wähnte, wenn man seine Hände nach gründlicher mechanischer Reinigung noch eine Zeit lang mit Sublimatlösung bearbeitet hatte. Schon vor mehreren Jahren aber hat Geppert auf das Irrthümliche dieser Ansicht hingewiesen und gezeigt, dass sehr wohl ron so behandelten Händen Culturen aufgehen, wenn man Vorsorge trifft, dass nichts von dem. Sublimat mit auf den künstlichen Nährboden übertragen wird. Seine Stimme aber verhallte - so scheint es - ungehört oder wenig beachtet. Man desinficirte weiter die Hände in der genannten Weise im festen Vertrauen, genug damit gethan zu haben. Dieses Vertrauen hat nun in jüngster Zeit durch die Arbeiten der Leipziger Frauenklinik und zuletzt durch Ahlfeld und Poten oinen merklichen Stoss erfahren. Es droht eine völlige Umwälzung auf diesem Gebiet. Ahlfeld hat durch eine grosse Zahl experimenteller. Untersuchungen nachgewiesen, dass die Desinfection der Finger mit Sublimat $(1 \%$ ohne Zuhilfenahme von Alkohol (Fürbringer) unsicher ist, dass dagegen die Desinfection mit 96 proc. Alkohol vorzügliche Resultate ergiebt. Er erzielte bei 52 Desinfectionsversuchen einzelner Finger 51 mal Sterilität. Poten prüfte die Resultate nach. Mit Sublimat gelang es ihm niemals, die Finger steril zu bekommen, während Alkoholdesinfection unter 44 Fällen 14 mal zum Ziele führte.

Als ich die Berichte der beiden Autoren las, war ich geneigt, die Poten'schen Resultate für die richtigen zu halten. Es war mir nicht recht glaublich, dass Ahlfeld, selbst wenn ihm die Sterilisirung der Finger gelungen sein sollte, mit so grosser Sicherheit zufällige Verunreinigungen vermieden haben sollte. Lässt man 
eine Gelatineplatte auch nur einen Moment der Luft ausgesetzt, so wachsen fast immer Culturen darauf. Ebenso, meinte ich, liessen sich auch sterile Finger nicht vor der Luftinfection bewahhren, und Culturversuche müssten in der Regel positiv ausfallen. Ich hatte wiederholt versucht, den Erfolg bezüglich Misserfolg der Desinfection meinen Schülerinnen durch Eintauchen der desinficirten Finger in Gelatineplatten zu demonstriren. Immer wuchsen Culturen, daher verzichtete ich in der Folge auf solche Demonstrationen. Tch fürchtete auf diese Weise das Gegentheil von dem $\mathrm{zu}$ beweisen, was ich zeigen wollte, und so anstatt Ueberzeugung Verwirrung zu schaffen.

Unverzüglich beschloss ich daher, die Ahlfeld'schen Versuche einer Nachprüfung zu unterziehen. Natürlich musste, um richtig vergleichen zu können, dieselbe Versuchsmethode gewählt werden. Es wurden also von den zu prüfenden Händen mit sterilen Hölzchen Hautschuppen, besonders unter dem Nagel und aus dem Nagelfalz gekratzt und dann sammt Hölzchen in Röhrchen mit Nährbouillon geworfen. Ich überzeugte mich bald, dass Röhrchen sich ganz anders zu den Versuchen eignen als Platten. Offenbar, weil hier zufällige Verunreinigungen viel leichter auszuschalten sind. Dementsprechend erhielt ich jetzt auch ganz andere Resultate. Versuche mit einzelnen Fingern habe ich nicht gemacht, weil in der Praxis nur die Desinfection der ganzen Hand und nicht nur einer, sondern beider Hände zuglejch in Betracht kommt. Die Hölzchen (halbe Zahnstocher) wạren einzeln in Fliesspapier gewickelt und in Dampf sterilisirt. Die Versuchsperson (Schülerinnen, Assistenten, Hebammen und ich) entnahm mit der einen Hand selbst das. Hölzchen der Papierhülle, nachdem diese von einer anderen Person vorsichtig ohne Berührung des Hölzchens aufgewickelt war und besorgte das Abkratzen von Hautschuppen von beiden Händen selbst.

Die Desinfection der Hände geschah in der üblichen Weise: Zuerst mechanische Reinigung mit warmem Leitungswasser, Seife und Bürste so lange, bis keine Spur von Schmutz mehr sichtbar war. Darauf drei Minuten langes Bürsten mit dem Desinfectionsmittel. Nach einigen Versuchen habe ich darauf verzichtet, steriles Wasser und sterile Waschschüsseln zu verwenden, denn das entspricht wieder nicht der Praxis. Fast jedesmal wurden Doppelversuche gemacht, d. h. es wurden je zwei Röhrchen beschickt.

Das Resultat, das wir gefunden haben, entsprach, um es vor- 
weg zu sagen, im Grossen und Ganzen dem, was Ahlfeld gefunden hat. Zunächst prüften wir die bei uns im Gebrauch befindlichen Desinfectionsmittel: Sublimat, Carbolsäure und Lysol. Es ergab sich, wie schon erwähnt, Folgendes: Nach Anwendung: von Sublimat ( $2 \mathrm{pCt}$.) erwiesen sich von 42 Händen 23 steril,

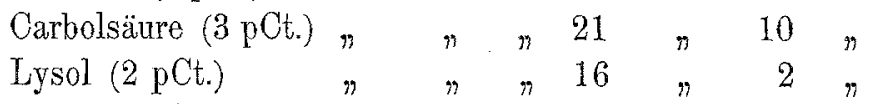

Nach diesem kläglichen Resultat stand ich davon ab, noch weitere Versuche mit diesen Mitteln anzustellen. Es war zur Genüge klar, dass sie werthlos sind. Es kommt dabei noch erschwerend in Betracht, dass wir es unterlassen haben, die Wirkung des an der Hand noch haftenden Desinfectionsmittels vor der Abkratzung der Hautschuppen zu paralysiren. Wenn auch ganz wenig, so ist doch immer etwas mit in die Bouillon übertragen worden.

Wir ersetzten nun die vorgenannten Mittel durch reinen Brennspiritus (96 pCt.). Unter 41 Versuchen erwiesen sich die Hände $36 \mathrm{mal}$ als steril, d. i. in 87,8 pCt. der Fall, ein Resultat, das genau dem Ahlfeld'schen entspricht. Er erzielte bei der Handdesinfection mit Alkohol 87,5 pCt. Sterilität.

Es fragt sich nun, wie ist diese Wirkung des Alkohols zu erklären. Zunächst muss man daran denken, ob nicht der mit den Hautschuppen zugleich in die Röhrchen übertragene Alkohol die Entwickelung von Culturen gehemmt hat. Dazu ist zu bemerken, dass nur ein spurweises Uebertragen von Alkohol stattgefunden haben kann; denn gewöhnlich war derselbe, ehe die Abschabung vollendet war, vollständig verdunstet. Hände, Hautschuppen und Hölzchen waren inzwischen meist ganz trocken geworden. Ausserdem habe ich folgenden Versuch $7 \mathrm{mal}$ wiederholt: Ich liess in ein frisches Bouillonröhrchen drei Tropfen Alkohol fallen. Dann schabte ich meine ungereinigte Hand mit einem Hölzchen $a b$ und warf es in dasselbe Röhrchen. Jedesmal trübte sich die Bouillon; manchmal allerdings später und weniger als in alkoholfreien Controlröhrchen. Wenn also drei dicke Tropfen Alkohol das Wachsthum von Keimen nicht gehindert haben, so kann es die Spur, die an den Schuppen bez. den Hölzchen haftete, erst recht nicht gethan haben.

Am nächsten liegt es, an eine bactericide Kraft des Alkohols zu denken. Dies zu erforschen habe ich folgende Versucho gemacht: 
1. Die Kuppe eines Reagirgläschens wurde mit schmutzigem Waschwasser von Händen gefüllt. Darüber wurde Spiritus gegossen, bis das Röhrchen zum dritten Theil voll war. Nach Durchmischung des Inhalts wurden 11 Bouillonröhrchen mit je einer Oese dieser Mischung beschickt und zwar nach 1, 2, 3, 5, $6,7,9,10,12,15$ und 30 Minuten. Alle Röhrchen blieben steril. Ein Controlröhrchen, das mit einer Oese desselben Schmutzwassers ohne Alkohol beschickt war, trübte sich sehr bald.

2. Die Kuppe eines Reagirgläschens wurde mit einer Bouilloncultur, die von Händewaschwasser gewonnen war, gefüllt. Darüber Alkohol wie im vorigen Fall gegossen und schnell umgeschüttelt. Entnahme von dieser Mischung je einer Oese und Uebertragung in Bouillon nach 1, 3, 5, 10, 16 Minuten. Sämmtliche Bouillonröhrchen blieben steril. Ein Controlröhrchen mit einer Oese reiner Waschwasser-Bouilloncultur entwickelte sehr bald Culturen.

3. Derselbe Versuch. Abimpfung nach 2, 4, 51/2, 10, 17 Minuten. Dasselbe Resultat, auch im Controlröhrchen.

Ahlfeld hat denselben Versuch gemacht, nur dass er statt unserer Waschwasser-Bouilloncultur ein Gemisch von Bouillonculturen verwendete, die von verschiedenen Händen gezüchtet waren. Er bekam in allen 12 beschickten Röhrchen Wachsthum, selbst nachdem der Alkohol 4 Stunden auf die Bouilloncultur eingewirkt hatte. Er schloss daraus, dass die Mikroben, die leicht durch Alkohol getödtet werden, nach einem Zwischenstadium, das sie in Bouillon durchleben, so an Resistenz gewinnen, dass sie nun dem Alkohol erfolgreich Widerstand leisten. Das scheint also nicht richtig zu sein; denn wir haben bei demselben Versuch, 2 mal wiederholt, immer ein negatives Resultat erhalten. Auch die folgenden Versuche sind mit unseren vorstehenden conform ausgefallen, abweichend von dem Resultate Ahlfeld's.

4. Anfüllung der Röhrchenkuppe mit einer StaphylokokkenGelatinecultur (aus Mammaabscess gezüchtet). Mischung mit Alkohol wie vor. Uebertragung je einer Dose dieser Mischung in Bouillon nach $1,1^{1} / 2,21 / 2,3^{1} / 2,4^{1} / 2,5^{1} / 2$ Minuten. Nirgends Wachsthum. Ein Controlröhrchen mit derselben Staphylokokkencultur beschickt, trübt sich.

5. Derselbe Versuch wie vorher mit Staphylokokkenbouilloncultur. Entnahme und Impfung nach 1, 2, 3, 4, 5 und 10 Minuten. Dasselbe Resultat. 
6. In einem mit Alkohol gefüllten Röhrchen wird ein Stückchen stinkende Placenta ausgeschüttelt. Uebertragung je einer Oese dieses inficirten Alkohols in Bouillon nach $1 \frac{1}{2}, 2 \frac{1}{2}, 4,5$, 9, 13 Minuten. Alle Röhrchen bleiben steril. Im Controlröhrchen, das mit einer Oese Jauche derselben Placenta beschiekt war, lebhaftes Wachsthum.

7. Mischung von Alkohol mit einer Kuppe von Streptokokkenbouilloncultur (gezüchtet aus dem Wochenfluss einer an Puerperalfieber mit tödtlichem Ausgang erkrankten Wöchnerin). Entnahme und Uebertragung in Bouilion nach 1, 2, 3, 4, 5, 8 Minuten. Allo Röhrchen bleiben steril; im Controlröhrchen. Wachsthum.

Die hohe baktericide Kraft des Alkohols ist damit erwiesen. Er tödtet Streptokokken und Staphylokokken nach 1 Minute. Dass die mit übertragene Oese Alkohol nicht die Entwicklung von Culturen gehemmt hat, geht aus dem schon früher mitgetheilten Versuche hervor, in dem mehrere Tropfen Alkohol und die Keime gesondert in ein Bouillonröhrchen eingebracht wurden und trotzdem Culturen angingen. Ausserdem habe ich verschiedene der steril gebliebenen Röhrchen nachträglich mit Nagelschmutz oder irgend einer Cultur beschickt. Es zeigte sich jetzt immer Wachsthum.

Ferner habe ich Alkohol, in welchem schmutzige Hände direkt gewaschen waren und auch Bodensatz von solchem Alkohol $12 \mathrm{mal}$ auf Bouillon übertragen. Niemals wuchs etwas. Poten hat in ähnlichen Versuchen immer Wachsthum erzielt. Ich vermag nicht zu sagen, woran das liegt, wenn es nicht die Verschiedenheit der Nährböden ist. Dass indessen nicht alle Mikroben durch Alkohol getödtet werden, beweist die Essiggährung desselben.

Um die baktericide Kraft des Sublimats mit derjenigen des Alkohols zu vergleichen, habe ich den Versuch 6 und 7 wiederholt und den Alkohol darin durch eine $2 \%$ Sublimatlösung ersetzt. Nur 1 Röhrehen zeigte Wachsthum, dort, wo Sublimat 2 Minuten lang auf Streptokokkenbouilloneultur eingewirkt hatte. Mikroskopisch fanden sich in diesem Röhrehen Streptokokken.

Also auch Sublimat hat eine hohe baktericide Kraft. Warum gelingt es dann aber so sehr viel schwerer die Hände mit Sublimat, als mit Alkohol zu sterilisiren? Ich glaube der Unterschied liegt hauptsächlich an der hohen Fähigkeit des Alkobols, in die Epidermis einzudringen. Er durchdringt die Oberhaut und tödtet damit die daran und darin sitzenden Mikroben. Wässerige Sublimatlösung dringt aber in die fettige Epidermis nicht ein. Sie tödtet 
höchstens die an der Oberfläche haftenden Keime. Die Keime, die zwischen und in den Epidermisschuppen ruhen, die wir lediglich bei unseren Versuchen verwandten, bleiben unberührt. - Die weitgehende mechanische Reinigung, die man mit Alkohol erreicht, kann nicht allein schuld sein, wie Poten unter Leugnung der baktericiden Kraft desselben annimmt. Denn tödtet Alkohol die Keime nicht, dann verstehe ich nicht, wie ich meine Hände aus Alkohol, der bei der Desinfection dieser Hände gründlich inficirt worden ist, keimfrei herausbringen kann.

Uebereinstimmend mit Reinicke, Ahlfeld und Poten haben wir festgestellt, dass vorläufig mit 96 procentigem Alkohol die bei weitem beste Sterilisirung der Finger zu erzielen ist. Sublimat, Kresol, Lysol, Carbolsäure stehen weit zurück. Ich babe auch noch die essigsaure Thonerde in meine Versuche einbezogen. Von einer Mischung des reinen Liquor aluminis acet. mit Streptokokkenbouilloncultur entnahm und übertrug ich in Bouillonröhrchen nach 1, 2, 3, 4, 5 und 8 Minuten. Alle Röhrchen zeigten Wachsthum. Nach diesem Resultat habe ich erst keine Handdesinfectionsversuche mit diesem Mittel gemacht.

Die mit Alkohol erzielten Resultate sind jedoch noch nicht ganz befriedigend. Es wird weiterer Arbeit bedürfen, um die beste Desinfectionsmethode ausfindig zu machen. Ich wünschte übrigens auch, dass der reine Alkohol nicht den ersten Platz behielte, aus dem einfachen Grunde, weil er viel zu theuer ist. Ausserdem ist es sehr misslich, so grosse Quantitäten, wie bei einer länger dauernden Geburt erforderlich sind, immer mit sich zu führen. Diesen Uebelständen wäre allerdings zum grossen Theil abgeholfen, wenn Alkohol in schwächerer Concentration dasselbe leistete. Darüber habe ich auch Versuche gemacht und gefunden, dass Alkohol, zur Hälfte mit Wasser verdünnt, ebenfalls schon nach 1 Minute Streptokokkenbouillonculturen im Reagensglase tödtet. 1/4 Alkohol (1 Theil Alkohol und 3 Theile Wasser) ergiebt dasselbe Resultat erst nach 3 Minuten langer Einwirkung. Schwächere Mischungen müssen ausser Betracht bleiben. Es fehlen noch die Handdesinfectionsversuche. Diese will ich nachholen, sobald ich wieder Schülerinnen, also viel. Versuchsobjecte, im Hause habe. Jetzt in der Cursus-freien Zeit würden solche Versuche zu lange Zeit beanspruchen. Es ist mir übrigens nicht bekannt, dass von anderer Seite verdünnter Alkohol geprüft worden wäre. Die Versuche mit Alkohol sind demnach noch nicht abgeschlossen. 
Bis dahin möchte ich auch noch davon abstehen, den Alkohol allgemein, wie z. B. für die Hebammenpraxis, zu empfehlen. Die rege Arbeit auf dem Gebiete der Desinfection fördert fortwährend neue Ergebnisse zu Tage. Wer weiss, ob nicht in Kürze noch eine zuverlässigere Methode gefunden wird. Eine zu häufige Abänderung so wichtiger Vorschriften wie derjenigen für die Desinfection erzeugt $Z_{w}$ eifel und mangelndes Vertrauen auf deren Zweckmässigkeit. Sie werden schliesslich gar nicht befolgt. Ehe wir also in der Desinfectionsfrage zum Abschluss gekommen sind, mag die altehrwürdige Carbolsäure in der Hebammenpraxis noch - hoffentlich nicht mehr für lange - beibehalten werden. Man erzielt auch mit ihr leidliche Resultate, wenn nur die mechanische Reinigung -- vielleicht das allein Wirksame dabei - gründlich besorgt und die innere Untersuchung recht schonend ausgeführt wird. Ich kann dies damit begründen, dass wir dabei keine schlechteren Resultate erzielt haben, als Ahlfeld mit der überlegenen Alkoholdesinfection. Der denkende Arzt wird jederzeit sich den jeweiligen Forschungsergebnissen zu accommodiren und sein Verfahren darnach zu modificiren verstehen. Wir werden den Alkohol jedenfalls bis auf Weiteres dann anwenden, wenn wir mit infectiösem Material zu thun gehabt haben. Auch vor Operationen werde ich mich fortan mit Alkohol desinficiren.

Wenn ich nach diesen Ausführungen zu der eingangs dieser Arbeit aufgestellten These No. 1 (S. 621) zurückkehre, so muss sie eine wesentliche Modification erfahren: Zunächst ist es vorläufig nicht richtig, dass die Leitung und Methode derjenigen Anstalt die beste ist, die am wenigsten Procent Fieberfälle aufzuweisen hat. Das kann erst dann zutreffen, wenn die Art der Temperaturmessung überall dieselbe ist. Ich bin überzeugt, dass sich alsdann überall viel höhere Zahlen ergeben werden, als heut von verschicdener Seite bekannt geworden sind, und dass die Statistik unsere Methode der möglichsten Enthaltung von allen inneren Eingriffen rechtfertigen wird. - Sodann bleibt es ein frommer Wunsch, es dahin zu bringen, dass unsere Wöchnerinnen $38^{\circ} \mathrm{C}$. niemals oder nur selten überschreiten. Temperatursteigerungen darüber hinaus sind eine häufige, unvermeidbare Erscheinung, ohne dass dadurch irgend wie der normale Ausgang des Wochenbetts gestört wird. Fs ist daher nicht angebracht, solche Wochenbetten zu den krankhaften zu zählen. Will man sie aber doch aus wissenschaftlichen Rücksichten - denn praktisch kann man sie zu den 
normalen rechnen - in eine besondere Gruppe zusammenfassen, so möchte ich sie am liebsten mit Zweifel als ngestörte Wochenbetten" bezeichnen. Als kranke Wöchnerinnen sind diejenigen zu bezeichnen, deren Erholung vom Geburtsacte nicht in der gewöhnlichen Zeit erfolgt.

Die zweite These (S.621) besteht zu Recht. Fiebert eine Wöchnerin, so muss unsere Therapie dahin zielen, die eingedrungenen Keime unschädlich zu machen. Diejenige Methode ist die beste, die das am schnellsten und ungefährlichsten erreicht. Der Hauptsache nach giebt es hier zwei Richtungen, die exspectative und die active. Bei der ersteren baut man auf die natürlichen Vertheidigungsmittel des Körpers, deren volle Entfaltung man vor Allem durch Ruhe erstrebt. Daher keinerlei innere Eingriffe. Man unterstütat vielmehr den kranken Körper im Kampfe um's Dasein mit den Mikroben, indem man ihn durch Diät, Alkohol, Bäder, Linderung der Schmerzen und sonstige symptomatische Behandlung bei Kräften zu erhalten sucht. Manche chirurgische Eingriffe, z. B. Eröffnung von Abscessen, gehören selbstverständlich auch hierher. Vertreter der activen Richtung überlassen diesen Kampf nicht allein dem Körper, sondern greifen den Feind durch lokale Behandlung des Genitalapparates, Scheidenspülungen, Gebärmutterspülungen, Aetzungen etc. selbst an. Dass ich den ersteren Weg für den richtigeren halte, geht aus Saft's Ausführungen hervor. Auch die Gründe dafür hat er entwickelt. Ich habe dem Nichts hinzuzufügen.

Wenn Saft zur Begründung unserer Anschauung nur die Leopold'sehen Forschungsergebnisse mit den unserigen vergleicht und kritisch beleuchtet, so ist dies ein Manco, das aber nicht wett zu machen ist, so lange nicht auch andere Forscher der activen Richtung mit gleich dankenswerther Sorgfalt die Details ihres Materials bekannt geben und auf diese Weise der Nachprüfung zugänglich machell. 